\title{
Higher-Order Epistemic Attitudes and Intellectual Humility
}

\author{
Allan Hazlett \\ Forthcoming in Episteme
}

Recent discussions of the epistemology of disagreement (Kelly 2005, Feldman 2006, Elga 2007, Christensen 2007) have focused on the question: how ought you respond to disagreement with an epistemic peer? ${ }^{1}$ These discussions have assumed that the question of the proper response to disagreement about $\mathrm{p}$ concerns whether you ought to change your doxastic attitude towards $\mathrm{p}$. Here I suggest an alternative approach, on which the question of the proper response to disagreement about $\mathrm{p}$ concerns the proper doxastic attitude to adopt concerning the epistemic status of your doxastic attitude towards p.

My discussion will focus on would-be necessary connections between doxastic attitudes about the epistemic statuses of your doxastic attitudes, or higher-order epistemic attitudes, and the epistemic statuses of those doxastic attitudes. ${ }^{2}$ I will argue that, in some situations, it can be reasonable for a person to believe $\mathrm{p}$ and to suspend judgment about whether believing $\mathrm{p}$ is reasonable for her. This will set the stage for an account of the virtue of intellectual humility, on which humility is a matter of your higher-order epistemic attitudes.

\section{$1 \quad$ Feldman's skeptical argument}

A crucial premise in Richard Feldman's (2006, 2007) argument for skepticism (suspension of judgment) about controversial matters in religion, politics, and philosophy is the following principle:

\footnotetext{
1 "Epistemic peer" is a term of art (Kelly 2005), referring to people who have equally good evidence (relevant to the question whether p) and who are equally epistemically virtuous (when it comes to answering the question whether $\mathrm{p}$ ).

${ }^{2}$ As will become clear, I intend "higher-order epistemic attitudes" to refer to attitudes about either actual or possible lower-order doxastic attitudes. In particular, we will be concerned with a person's attitudes about whether believing $\mathrm{p}$ is reasonable for her $(\$ 2)$, where believing $\mathrm{p}$ can be reasonable for $\mathrm{S}$ even when $\mathrm{S}$ doesn't believe $\mathrm{p}$.
} 
Feldman's principle: If you suspend judgment about whether believing $\mathrm{p}$ is reasonable for you, then you ought to suspend judgment about $\mathrm{p} .{ }^{3}$

Here's why this premise is crucial for Feldman's argument (2006, pp 230-33). On the basis of the principle of epistemic uniqueness, Feldman argues that

Premise: If you disagree with an epistemic peer about $\mathrm{p}$, then you ought to suspend judgment about whether believing $\mathrm{p}$ is reasonable for you. ${ }^{4}$

The conclusion Feldman seeks is:

Conclusion: Epistemic peers that disagree about $\mathrm{p}$ ought to suspend judgment about $\mathrm{p}$.

Feldman's Principle provides the required connecting premise. But why accept it?

\section{$2 \quad$ Arguments for Feldman's principle}

In this section I criticize arguments for Feldman's principle. First, some preliminaries. I assume three doxastic attitudes: belief, disbelief, and suspension of judgment. Disbelief is therefore distinct from not believing. And I assume suspension of judgment about $\mathrm{p}$ is an attitude towards $\mathrm{p}$; it is distinct from taking no attitude towards $\mathrm{p}$, and distinct from neither believing nor disbelieving $\mathrm{p}$.

We will speak of reasonable belief, reasonable disbelief, and reasonable suspension of judgment. These notions are subject-relative: believing $\mathrm{p}$ may be reasonable for me but not reasonable for you (e.g., if we have different evidence). To say that believing $\mathrm{p}$ is reasonable for someone does not entail that she believes $\mathrm{p}$, and likewise for the other doxastic attitudes, for someone can fail

\footnotetext{
${ }^{3}$ For simplicity we confine ourselves to situations in which people enjoy a kind of transparency of their situation: someone who suspends about $\mathrm{p}$ is assumed to be aware that she suspends about $\mathrm{p}$, epistemic peers are assumed to be aware that they are peers, and so on.

${ }^{4}$ Here I grant, for the sake of argument, this premise and the principle of epistemic uniqueness.
} 
to believe what is reasonable for her to believe. We will say that someone's doxastic attitude towards $\mathrm{p}$ is reasonable iff she adopts that doxastic attitude towards $\mathrm{p}$ and that doxastic attitude towards $\mathrm{p}$ is reasonable for her.

Whenever possible we will remain neutral when it comes to the nature of reasonable belief, but because many defenders of Feldman's principle are evidentialists about reasonable belief $(\$ 2.1$, \2.3), we will often treat reasonable belief as supervening on evidence. While the notion of the "epistemic" is ambiguous and unclear, we shall assume that the notion of reasonableness at play here is epistemic reasonableness (Feldman 2006, p. 221).

Second, a sympathetic amendment to Feldman's principle. Consider:

Anne, a highly intelligent expert in syllogistic logic, deduces, from the fact that Aristotle is a man and the fact that all men are mortal, that Aristotle is mortal. But she then suffers from a fit of anxious, non-rational panic, becomes irrationally self-critical and self-doubting, wonders whether she is capable of performing a deduction of this complexity, and for no good reason comes to suspend judgment about whether believing that Aristotle is mortal is reasonable for her.

You might deny that Anne ought to suspend judgment about whether Aristotle is mortal. She has extremely good evidence supporting the proposition that Aristotle is mortal, she has no evidence whatsoever against that proposition, and her higher-order epistemic attitude is by hypothesis completely unreasonable. If it is false that Anne ought to suspend judgment about whether Aristotle is mortal, then we should amend Feldman's principle:

Feldman's principle, amended: If you reasonably suspend judgment about whether believing $\mathrm{p}$ is reasonable for you, then you ought to suspend judgment about $\mathrm{p}$. 
Given this amendment, in what follows we will assume cases in which a person's higher-order epistemic attitudes are reasonable. The unamended principle entails the amended principle; the amended principle is therefore weaker than the amended principle. Thus, if the amended principle is false, then so is the unamended principle.

\subsection{The argument from respecting the evidence}

Consider the view that you ought always "respect the evidence," where:

[A] person is respecting the evidence about $\mathrm{E}$ and $\mathrm{P}$ when the person's belief concerning $\mathrm{P}$ corresponds to what is indicated by the person's evidence about E's support for $\mathrm{P}$. That is, a person respects the evidence about $\mathrm{E}$ and $\mathrm{P}$ by believing $\mathrm{P}$ when [and only when] his or her evidence indicates that this evidence supports $\mathrm{P}$ or by not believing $\mathrm{P}$ when [and only when] the evidence indicates that this evidence does not support P. (Feldman 2005, pp. $95-6)^{5}$

We'll call the view that you ought always respect the evidence the respect view. Note well that the respect view does not entail that reasonably believing $\mathrm{p}$ requires a reasonable higher-order belief to the effect that believing $\mathrm{p}$ is reasonable. Defenders of Feldman's principle (Bergmann 2005, p. 419, Feldman 2005, p. 111) rightly reject this version of the controversial "JJ" principle, on which someone is justified in believing $\mathrm{p}$ only if she is justified in believing that she is justified in believing $\mathrm{p}$ (cf. $\$ 2.3)$.

Although this is not explicit in Feldman's formulation, we should take respecting the evidence to require that a person suspend judgment about $\mathrm{p}$ when and only when her evidence indicates that her evidence supports neither $\mathrm{p}$ nor not-p (as well as requiring that a person disbelieve $\mathrm{p}$ when

\footnotetext{
${ }^{5}$ I have added "and only when," which is implied by the first quoted sentence, and required if the view described here provides support for Feldman's principle.
} 
and only when her evidence indicates that not-p). In other words, we should understand respecting the evidence to require believing $\mathrm{p}$ when and only when your evidence indicates that your evidence supports $\mathrm{p}$, disbelieving $\mathrm{p}$ when and only when your evidence indicates that your evidence supports not-p, and suspending judgment about $\mathrm{p}$ when and only when your evidence indicates that your evidence supports neither $\mathrm{p}$ nor not-p.

We can defend Feldman's principle by appeal to the respect view. Suppose that S reasonably suspends judgment about whether believing $\mathrm{p}$ is reasonable for her. Given two assumptions, we can infer from this that S's evidence indicates that her evidence supports neither p nor not-p. The first assumption is that someone reasonably suspends judgment about whether believing $\mathrm{p}$ is reasonable only if she reasonably suspends judgment about whether her evidence supports p. The second assumption is that someone reasonably suspends judgment about whether her evidence supports $\mathrm{p}$ only if her evidence indicates that her evidence supports neither $\mathrm{p}$ nor notp. Both assumptions could plausibly be called evidentialist, if we take evidentialism about reasonable belief to be the view that whether a doxastic attitude is reasonable for $\mathrm{S}$ supervenes only on S's evidence (see \$2.3). Now if S's evidence indicates that her evidence supports neither $\mathrm{p}$ nor not-p, it follows from the respect view that $\mathrm{S}$ ought to suspend judgment about $\mathrm{p}$. Therefore, Feldman's principle is true.

If we grant our two evidentialist assumptions, therefore, the question of whether Feldman's principle is true comes down to the question of whether the respect view is true. Is it? That question is complicated by the fact that there are a number of distinct aspects of respecting the evidence, as we noted above. For our purposes, note that the person who respects the evidence will abide by both of the following:

Undercutting principle: If you reasonably believe that believing $\mathrm{p}$ is not reasonable for you, then you ought not believe p. 
Feldman's principle: If you reasonably suspend judgment about whether believing $\mathrm{p}$ is reasonable for you, then you ought to suspend judgment about p.

These two principles are logically independent; importantly, the undercutting principle does not entail Feldman's principle. Roderick Chisholm (1989) makes this point in connection with the legitimacy of pursuing "the task of traditional epistemology" while suspending judgment about whether its "presuppositions are justified." (p. 6) He writes:

One may object, "But it is unreasonable to proceed if you do not think you are justified in proceeding!" The answer is ... that that is not unreasonable. What is unreasonable is to proceed when you think you are not justified in proceeding. And from the fact that you do not think you are justified, it does not follow that you do think you are not justified. (Ibid.)

This means that there may be intuitive support for the undercutting principle that doesn't support Feldman's principle. Consider a case in which I reasonably believe that some belief of mine is unreasonable: I've just solved a logic puzzle, but then I'm told by a reliable informant that my coffee has been laced with a drug that causes "almost invariable" failure on logic puzzles in $80 \%$ of the people who take it (Christensen 2010, p. 187). Intuitively, I ought not believe that the answer I arrived at is correct. This is a consequence of the undercutting principle, and so that principle has some intuitive support. But this support is neutral as to Feldman's principle. The same point applies to Feldman's case (2005, p. 96-7) of the student who is reasonably convinced of Cartesian skepticism and Christensen's case (2010, p. 197) of the juror who is given "strong evidence" that she has been drugged.

We have articulated a partial defense of Feldman's principle: if the respect view is true, then Feldman's principle is true. But we have not considered whether the respect view is true. Below 
$(\$ 2.4, \S 2.5)$ we will consider arguments in defense of the respect view. But we must keep in mind that we seek arguments that support Feldman's principle in particular; arguments that only support the undercutting principle do not support the respect view per se.

\subsection{The argument from undercutting defeaters}

Another way of articulating the idea that your higher-order epistemic attitudes affect the epistemic statuses of your corresponding lower-order doxastic attitudes is by appeal to the notion of an undercutting defeater (Bergmann 2005, pp. 422-7, Feldman 2005, p. 104, Christensen 2010, pp. 193-9, Huemer 2011, pp. 7-9). A rebutting defeater for believing p is evidence that $\mathrm{p}$ is false; an undercutting defeater for believing $\mathrm{p}$ is evidence that you do not have evidence that warrants believing p. You might defend Feldman's principle by appeal to the premise that suspension of judgment about whether believing $\mathrm{p}$ is reasonable for you constitutes an undercutting defeater for believing $\mathrm{p}$.

Is this argument any good? The main problem with it is that it does not get us very far. For why should we think that suspension of judgment about whether believing $\mathrm{p}$ is reasonable constitutes an undercutting defeater for believing p? The question of whether Feldman's principle is true, in some sense, just is the question of whether suspension of judgment about whether believing $\mathrm{p}$ is reasonable for you constitutes an undercutting defeater for believing p. That such suspension constitutes an undercutting defeater isn't a cogent reason to think that Feldman's principle is true; nor does it provide any explanation of why Feldman's principle is true. At the very least, we will need an argument that such suspension does constitute an undercutting defeater.

Consider Michael Bergmann's (2005) discussion of undercutting defeaters, in defense of the view that "an attitude of significant uncertainty about the proposition that your actual ground or reason for $b$ is indicative of $b$ 's truth" constitutes an undercutting defeater for believing $b$ (p. 427). Bergmann begins by defining an undercutting defeater for $b$ as "a defeater which is $\ldots$ the 
belief that your actual ground or reason for $b$ is not indicative of $b$ 's truth.” (Ibid. p. 424)

Bergmann then considers the question of whether suspending judgment about whether your grounds are good also constitutes an undercutting defeater. "I think it does," he writes, since suspension "seems to undercut your justification for believing $p$ in the same way as if you believed outright that the actual basis for your belief that $p$ did not indicate $p$ 's truth.” (Ibid. p. 426) Perhaps Bergmann is appealing to intuition here, in support of Feldman's principle, but we don't have any kind of argument that such suspension constitutes an undercutting defeater. Importantly, from the premise that believing your grounds for believing $\mathrm{p}$ are inadequate constitutes an undercutting defeater for believing $\mathrm{p}$, it does not follow that suspending judgment about whether your grounds for believing $\mathrm{p}$ are good constitutes an undercutting defeater for believing p. (Recall that the undercutting principle does not entail Feldman's principle.)

\subsection{The argument from evidentialism}

Bergmann writes that:

Internalist theories of epistemic justification tend to require for justification of a belief $b$ that anyone holding $b$ must have a certain perspective on it, must conceive of $b$ as having something or other going for it. (2005, p. 419)

If there is such a general "higher-level requirement" on reasonable belief, then Feldman's principle is plausible, along with many other necessary connections between your higher-order epistemic attitudes and the epistemic statuses of your lower-order doxastic attitudes. Someone committed to internalism, in Bergmann's sense, might therefore have good reason to endorse Feldman's principle. But for those not so committed, this will just raise the question of whether there are any general higher-level requirements on reasonable belief. As noted above (\$2.1), such requirements are controversial. 
We should note that Feldman's principle is not entailed or supported by those views, also called "internalist," on which the factors that justify a belief must be "internal" factors, where "internal" can be understood in various ways, e.g. in terms of the mental states of the believer, or in terms of the believer's access to said factors, and so on. So, for example, some internalists would argue that justified belief requires the believer to have access to good reasons for said belief. Internalism, in this sense, does not entail or support Feldman's principle. This is why Feldman is right to point out that the question of whether the respect view is true is orthogonal to the internalism/externalism debate (2005, pp. 105-7).

Is Feldman's principle entailed or supported by some particular internalist theory, such as evidentialism about reasonable belief (\$2.1)? We appealed to two evidentialist assumptions, above, in our argument that the respect view entails Feldman's principle. In that respect, evidentialism supports Feldman's principle. But the argument's crucial premise is the respect view, and the respect view is not entailed or supported by evidentialism. Evidentialism, recall, says that whether a doxastic attitude is reasonable for S supervenes only on S's evidence. The respect view tells us specifically how S's evidence determines the reasonable doxastic attitude for her: it says that the reasonable doxastic attitude is determined by what S's evidence indicates about what S's evidence supports. The respect view is not equivalent to the view that your doxastic attitude towards $\mathrm{p}$ ought always be the doxastic attitude towards $\mathrm{p}$ that is warranted by your evidence. The respect view is the view that your doxastic attitude towards p ought always be the doxastic attitude towards $\mathrm{p}$ that your evidence indicates is warranted by your evidence. An evidentialist about reasonable belief could therefore consistently deny the respect view.

To see this, imagine a situation in which S has evidence E1, which strongly supports $\mathrm{p}$, and then acquires a new piece of evidence, E2, which strongly supports the proposition that E1 does not support p. (E2 is therefore misleading evidence, see \$3.2) What is it reasonable for $\mathrm{S}$ to believe, on the basis of her total evidence, E1+E2? Evidentialism is neutral on this question; it just says 
that S's evidence fully determines what it is reasonable for her to believe, i.e. that nothing other than the fact that $\mathrm{S}$ has evidence $\mathrm{E} 1+\mathrm{E} 2$ is relevant to the question of what it is reasonable for her to believe. The respect view says that it is not reasonable for $\mathrm{S}$ to believe p, given E1+E2. But it is consistent with evidentialism to deny this.

We should note that some theories of evidence do not jibe with the idea that your reasonable higher-order epistemic attitudes always provide evidence. Consider Timothy Williamson's (2001, pp. 184-208) identification of a person's evidence with what she knows. If I falsely, but reasonably, believe that my evidence does not support believing $\mathrm{p}$, this does not mean that I have defeating evidence for believing $\mathrm{p}$, on Williamson's view. For my reasonable belief does not constitute knowledge. In general, if you think that evidence must be constituted by facts, then you will have reason to reject the idea that reasonable higher-order epistemic attitudes always provide evidence, because higher-order epistemic attitudes can be false. If the defender of Feldman's principle wants to say that the principle is true because suspension of judgment about whether believing p is reasonable is evidence (Feldman 2005, Christensen 2010), she must reject the view that evidence is constituted by facts (or has factual content), in favor of the view that non-factive mental states can be evidence (cf. Bergmann 2005, p. 422).

\subsection{The argument from the principle that there are no propositions that can't be both true and reasonably believed}

Feldman (2005) argues that denying the respect view commits us to the view that someone could reasonably believe something of the following form:

(1) $\mathrm{p}$, but believing $\mathrm{p}$ is not reasonable for me.

Assuming evidentialism about reasonable belief, this will commit us to the view that someone could reasonably believe:

(2) p, but my overall evidence does not support $\mathrm{p}$. 
This, Feldman argues, is “extremely odd," (Feldman 2005, p. 108, see also 2006, p. 233) and Bergmann writes that "it is an epistemically bad state of affairs if I believe both that $p$ and that my belief that $p$ is not formed in a trustworthy way." (2005, p. 424) Let us grant that these two commitments are counterintuitive. However, they are not actually entailed by the negation of the respect view, as someone might reject the respect view by rejecting the idea that you ought to suspend judgment about $\mathrm{p}$ when and only when your evidence indicates that your evidence supports neither $\mathrm{p}$ nor not-p, while embracing the idea that you ought not believe $\mathrm{p}$ when and only when your evidence indicates that your evidence doesn't support p. In other words, someone might reject the respect view by rejecting Feldman's principle, while embracing the undercutting principle. Because we are concerned here with a defense of the respect view that will ground an argument for Feldman's principle (\$2.1), the oddity of (1) and (2) is orthogonal to our concerns. What we need to consider are:

(3) $\mathrm{p}$, but I suspend judgment about whether believing $\mathrm{p}$ is reasonable for me.

(4) p, but I suspend judgment about whether my overall evidence supports p.

Feldman says that this, too, "sounds odd." (2005, p. 105, 2006, p. 233) Why think that this really is odd? Why think that you couldn't reasonably believe (3) or (4)?

Feldman argues that what is problematic about the view that you might reasonably believe (2) is that (2) cannot be both true and reasonably believed, and therefore cannot be known. This follows from the assumptions that reasonable belief requires evidential support and that knowledge is a species of true, reasonable belief. " "One wonders," Feldman asks, "what circumstances could make belief in [(2)] reasonable.” (2005, p. 109) However, this point doesn't apply to (3) and (4). Both (3) and (4) could be true and reasonably believed. So, even if we concede that it is problematic to say that you might reasonably believe (1) or (2), on the grounds

\footnotetext{
${ }^{6}$ We must also assume that believing the proposition that $\mathrm{p}$ and $\mathrm{q}$ requires, or at least involves in the relevant case, believing $\mathrm{p}$.
} 
that (1) and (2) cannot be known, there is no such problem with saying that you might reasonably believe (3) or (4), since both could be known.

Feldman's question, however, of what circumstances would make belief in these propositions reasonable, deserves an answer. We'll return to that question below (\$3.2), where I'll argue that misleading evidence about the epistemic status of your beliefs can make it reasonable to suspend judgment about whether believing $\mathrm{p}$ is reasonable for you, even though believing $\mathrm{p}$ is reasonable for you.

\subsection{The argument from higher-order evidence}

Feldman offers a second argument against the view that you might reasonably believe (2), which appeals to the premise that "[w]e clearly can sometimes reason to object-level conclusions from information about evidence." (2005, p. 109) For example, it would be reasonable to believe p if you knew that $\mathrm{q}$ and that $\mathrm{q}$ is good evidence for $\mathrm{p}$. Feldman then argues that "it is very difficult to see why something similar would not be suitable when the information is that the evidence does not support the conclusion." (Ibid. p. 110) The argument, in other words, is that if (a) is a piece of good reasoning, then so is (b):

(a) $\mathrm{q}, \mathrm{q}$ is good evidence for $\mathrm{p}$, therefore $\mathrm{p}$.

(b) $\mathrm{q}$ is the only evidence I have relevant to $\mathrm{p}$, $\mathrm{q}$ is not good evidence for $\mathrm{p}$, therefore I suspend judgment about p.

There are two problems with Feldman's argument. First, the conclusion, that (b) is a piece of good reasoning, does not follow from the premise, that (a) is a piece of good reasoning. To put that point another way, from the fact that higher-order evidence sometimes makes a difference as to the reasonableness of a lower-order doxastic attitude, it does not follow that higher-order evidence makes a difference as to the reasonableness of lower-order doxastic attitudes in any particular way. 
Second, in connection with Feldman's principle, this argument is not relevant to whether you might reasonably believe (3) or (4). What would be needed is an argument that (c) is a piece of good reasoning:

(c) $\mathrm{q}$ is the only evidence I have relevant to p, I suspend judgment about whether $\mathrm{q}$ is good evidence for $\mathrm{p}$, therefore I suspend judgment about $\mathrm{p}$.

Suppose we concede that (b) is a piece of good reasoning. It does not follow that (c) is a piece of good reasoning. (Recall that the undercutting principle does not entail Feldman's principle.) So Feldman's argument does not give us any reason to believe that (c) is a piece of good reasoning, and therefore it does not give us any reason to think that believing (3) or (4) cannot be reasonable.

There is a special problem with the idea that suspension of judgment about the epistemic status of believing $\mathrm{p}$ provides evidence relevant to the question of whether to believe p. As we saw above (\$2.3), we require a conception of evidence on which non-factive mental states provide evidence. On this view, for example, the belief that $\mathrm{p}$ provides evidence for $\mathrm{p} v \mathrm{q}$. However, note that what explains this is the fact that the belief that $\mathrm{p}$ represents as true something that entails $\mathrm{p} \mathrm{v} \mathrm{q.} \mathrm{The} \mathrm{belief} \mathrm{that} \mathrm{p}$ provides evidence in virtue of what it represents as true - namely, the proposition that $\mathrm{p}$. This point applies in general to states of belief and disbelief: they provide evidence in virtue of the contents they represent as true. In light of this, it is puzzling how suspension of judgment can provide evidence. For suspension of judgment does not represent its propositional content as true. This is relevant to our distinction between Feldman's principle and the undercutting principle. It is easy to explain how the belief that believing $\mathrm{p}$ is not reasonable provides evidence relevant to the question of whether to believe $\mathrm{p}$ : the higher-order belief represents as true the proposition that believing $\mathrm{p}$ is not reasonable, and the truth of this proposition is relevant to the question of whether to believe $\mathrm{p}$. Thus we might offer an explanation of why the undercutting principle is true: the belief that believing $\mathrm{p}$ is not reasonable 
provides higher-order evidence relevant to the question of whether to believe $\mathrm{p}$; it is a defeater for believing $\mathrm{p}(\$ 2.2)$. But we cannot offer this kind of explanation in the case of Feldman's principle, as suspension of judgment about $\mathrm{p}$ does not represent $\mathrm{p}$ as true (or as not true). It is therefore obscure how suspension of judgment can provide evidence.

In any event, it is clear that the way in which suspension of judgment provides evidence is importantly different from the way in which belief and disbelief provide evidence. For the same reason, the way in which suspension of judgment might provide an undercutting defeater is importantly different from the way in which belief and disbelief might provide undercutting defeaters. The reason this is important is that defenders of Feldman's principle (Bergmann 2005, Feldman 2005, Huemer 2011) typically think of the undercutting principle and Feldman's principle as standing or falling together, as equally intuitive, or as two aspects of the same phenomenon. The present point shows why it is important to treat these two principles separately.

\subsection{The argument from Moore's paradox}

Michael Huemer (2011) argues that it is irrational to believe p while suspending judgment about whether your belief constitutes knowledge. This is a corollary of what he calls the "metacoherence requirement," on which "categorically believing that P commits one, on reflection, to the view that one knows that P.” (Ibid. pp. 1-2) If this is right, then surely Feldman's principle is. If reasonable belief cannot be combined with suspension of judgment about whether your belief constitutes knowledge, surely it cannot be combined with suspension of judgment about whether your belief is reasonable. This, on the assumption that knowledge requires reasonable belief and more, that the requirements for knowledge are more demanding than those for reasonable belief. Why think, with Huemer, that it is irrational to believe $\mathrm{p}$ while suspending judgment about whether your belief constitutes knowledge? 
Huemer motivates the metacoherence requirement by appeal to "Moore's Paradox." (2011, p. 6) Suppose it is possible to reasonably believe $\mathrm{p}$ while suspending judgment about whether your belief constitutes knowledge. "[S]ince assertion is the canonical expression of belief," it follows that, "barring any unusual circumstances," (Ibid.) someone could appropriately assert something of the form:

(5) p, but I suspend judgment about whether my belief constitutes knowledge.

However, so the argument goes, it is impossible to appropriately assert (5), for the same reason that it is impossible to appropriately assert (6):

(6) p, but I don't believe p.

Feldman (2005, p. 105, 2006, p. 233) may have a similar argument in mind when he appeals to the "oddity" of asserting (2) and (4).

As Huemer concedes (Ibid. pp. 6-7), what is ultimately distinctive about (6) is not that it is impossible to appropriately assert it, but that it is impossible to rationally believe it. So Huemer's argument should be recast as appealing to the premise that it is impossible to rationally believe (5), for the same reason that it is impossible to rationally believe (6). But this premise is false. The reason it is impossible to rationally believe (6) is that you cannot believe it and end up believing something true. ${ }^{8}$ The "Moore paradoxical" thought is the opposite of Descartes' cogito thought. If you think the thought "I exist," then your belief is guaranteed to be true, even though its content is contingent (and therefore possibly false). If you think the thought "It's

\footnotetext{
${ }^{7}$ This is the sentence that Moore found "paradoxical": "Though I don't believe it's raining, yet as a matter of fact it really is raining." (1993, p. 207)

${ }^{8}$ Assuming, again, that believing the proposition that $\mathrm{p}$ and $\mathrm{q}$ requires, or at least involves in the relevant case, believing p.
} 
raining, but I don't believe it's raining," your belief is guaranteed to be false, even though its content is contingent (and therefore possibly true). However, (5) does not have this feature.'

You might appeal at this point to the thesis that knowledge is the norm of assertion, on which it is proper to assert p only if you know that $\mathrm{p}$ is true (Williamson 1996, DeRose 2002; cf. Weiner 2006). If this thesis is true, then asserting (5) would amount to asserting “"p, but I don't know whether this assertion is proper," and you might think this is always inappropriate to assert.

I have been defending the view that it is sometimes reasonable to believe $\mathrm{p}$ while suspending judgment about whether your belief constitutes knowledge. Even if we concede that it is always inappropriate to assert (5), this does not conflict with the view I have been defending, so long as it is possible to reasonably believe something that would always be inappropriate to assert. Most of the things that you reasonably believe would not be appropriate to assert, so there is no general incoherence in saying that $\mathrm{S}$ reasonably believes $\mathrm{p}$ and that it would be inappropriate for $\mathrm{S}$ to assert p. Huemer may deny this; he takes the fact that "assertion is the canonical expression of belief" to mean that, in general, someone who believes p could appropriately assert p (2011, p. 6). This is not plausible; belief, or reasonable belief, or knowledge, or truth, may be necessary for appropriate assertion, but none are sufficient. So, in response to the objection from the knowledge norm of assertion, our reply is that the impossibility of appropriately asserting (5) does not entail or suggest that it is impossible to reasonably believe (5).

Above we conceded that asserting (5) is always inappropriate. But this concession should be challenged as well. Let us grant the knowledge norm of assertion; it is not obvious that it is incoherent to assert something that amounts to "p, but I don't know whether this assertion is proper." Perhaps it would be incoherent to assert something that amounts to "p, but this assertion isn't proper," e.g. (according to the knowledge norm) "p, but I don't know p." But this

\footnotetext{
${ }^{9}$ Neither, for that matter, does:

(7) p, but I don't know p.
} 
does not mean that it would be improper to assert something that amounts to " $p$, but I don't know whether this assertion is proper." There are many actions that you can coherently perform while suspending judgment about their propriety: when faced with a choice of three unfamiliar real ales, I choose one at random, not knowing whether this is the ale I ought to choose, i.e. not knowing if it's the best of the three, or even if it's any good, or even if it's worth drinking at all. It would be irrational to choose an ale I know to be an improper choice; perhaps in general it would be irrational to $\Phi$ when you think that you ought not $\Phi$. But this doesn't entail that it would be irrational to $\Phi$ when you suspend judgment about whether you ought to $\Phi$. (Again, recall that the undercutting principle does not entail Feldman's principle. $)^{10}$

What would be needed, to show that believing (5) is always irrational, is the view that knowledge is the norm of belief: that S's belief that $\mathrm{p}$ is rational iff S knows that $\mathrm{p}$. But that is not plausible.

Above I suggested that "Moore paradoxical" propositions are those that cannot be truly believed. If this is right, then (5) is not "Moore paradoxical." But this is a happy result, for it is not intuitive that asserting (5) is always improper. I believe that the Red Sox will win the AL East this year, but I would not claim to know that they will win. I believe that they will win, but I suspend judgment about whether my belief amounts to knowledge. There is no "paradoxical air" (Huemer 2011, p. 4) here, no sense of incoherence or impropriety. Similarly, there is no sense of incoherence in my thinking this thought: that the Red Sox will win, but I may not know that they will win.

\section{$3 \quad$ Against Feldman's principle}

\footnotetext{
${ }^{10}$ You could motivate Feldman's principle by appeal to the thesis that, necessarily, S ought to $\Phi$ only if S reasonably believes that she ought to $\Phi$. This thesis treats facts about what someone ought to do as transparent - as necessarily reasonably believed by her. Realism about some domain is often articulated as the view that the truths in that domain are not transparent. What it is for these truths to be "real" is for them to be independent of our ability to know them. If we are realists about epistemic 'oughts', therefore, we should not expect the facts about epistemic 'oughts' to be transparent.
} 
So far $(\$ 2)$ we have found no sound argument for Feldman’s principle. For all that, the principle might be true. So in this section I advance an argument against Feldman's principle.

\subsection{The argument from naïve liberalism}

As Feldman points out (2007, pp. 194-5), the conclusion of his argument (\$1) contradicts the naïve, common-sense view that reasonable peer disagreement about religion, politics, and philosophy is possible. Call this common-sense view naïve liberalism. Feldman's conclusion contradicts this, on the assumption that we have epistemic peers who disagree with us about religion, politics, and philosophy. So if we can find a sensible way of rejecting Feldman's principle, we will be justified in doing so, by way of preserving naïve liberalism, which is threatened by Feldman's argument. But we have already done this: by criticizing the arguments on offer in defense of Feldman's principle. We have prima facie reason to reject Feldman's principle (since it threatens naïve liberalism), and we have found no reason to accept it (\$2).

Our epistemological approach here should be analogous to that often employed in connection with skepticism about the external world, where naïve anti-skepticism is preserved so long as a sensible way of rejecting the premises of skeptical arguments can be found. If this approach is legitimate in the case of naïve anti-skepticism, it is also legitimate in the case of naïve liberalism. Consider a principle that might be appealed to in defense of skepticism about the external world: that it is reasonable to believe $\mathrm{p}$ only if you can give a non-circular argument in defense of $\mathrm{p}$. Common-sense anti-skeptical epistemologists reject this principle on the grounds that it leads to skepticism about the external world. Likewise, common-sense naïve liberals should reject Feldman's principle.

Moreover, Feldman's principle is counterintuitive. For, along with naïve liberalism, it is intuitive that at least one reasonable response to some peer disagreements is to suspend judgment about whose belief is reasonable, or whose belief amounts to knowledge. Imagine a case of religious 
disagreement between Julia, a theist, and Maria, an atheist, who are epistemic peers. After prolonged discussion that fails to settle the matter (by Julia and Maria's lights), it could be reasonable for Julia to respond "We must agree to disagree; one of us is right, and the other wrong, but it is unclear which of us is reasonable in our religious belief (if either of us is). Therefore, we should suspend judgment about the reasonableness of our beliefs. But I still believe that it is my theistic belief that is true."

Denying Feldman's principle allows us to see how this response might be reasonable. We would need to say more, however, to see how this response might be reasonable for both Julia and Maria. ${ }^{11}$ For all we have said here, at most one of Julia and Maria's religious beliefs is reasonable, and thus, for all we have said here, at most one of Julia and Maria might reasonably maintain her religious belief while suspending judgment about the reasonableness of said belief. But because peer disagreement sometimes seems to warrant suspension of judgment about the epistemic status of your beliefs, without requiring that you give up said beliefs, we should reject Feldman's principle.

You might resist this argument against Feldman's principle by arguing that naïve liberalism can be preserved by rejecting Feldman’s other premise (\$1), e.g. by rejecting epistemic uniqueness. But the only way reasonable peer disagreement can be preserved is if peer disagreement never requires suspension of judgment about the reasonableness of your beliefs. Although there may be mutually recognized reasonable peer disagreements, I have suggested that in some cases the reasonable response is to suspend judgment about the reasonableness of your (and your peers) doxastic attitudes. ${ }^{12}$

\footnotetext{
${ }^{11}$ I pursue this possibility in "Entitlement and Reasonable Disagreement."

${ }^{12}$ I have suggested an epistemological methodology that seeks to preserve naïve liberalism. We might similarly seek to preserve political liberalism, e.g. as articulated by Rawls 1996, in our epistemology. The view suggested here (that peer disagreement sometimes requires suspension of judgment about the reasonableness of your beliefs while permitting retention of said beliefs, see also \$4) jibes with political liberalism: the neutral higher-order epistemic attitude ensures
} 


\subsection{Misleading higher-order evidence}

Recall a question that we left unanswered above (\$2.4): in what circumstances will it be reasonable to believe $\mathrm{p}$ while suspending judgment about whether believing $\mathrm{p}$ is reasonable? I propose that this can be reasonable when you have good lower-order evidence for $\mathrm{p}$ and misleading higher-order evidence about the reasonableness of believing $\mathrm{p}$.

Misleading evidence is no fun, epistemically speaking. Misleading evidence can make it reasonable to believe falsehoods; it can rob you of your knowledge when it warrants suspension of judgment about something you would otherwise know. And misleading higher-order evidence brings new threats. Christensen argues that misleading higher-order evidence "often seems to require agents to bracket certain reasons, resulting in their failing to respect the relevant epistemic relations." (2011, p. 202) There can seem to be "something epistemically wrong with an agent's beliefs after she takes correct account of' higher-order evidence (Ibid. p. 204) On Christensen's view, this is because of the fact that misleading evidence about whether your lower-order evidence supports $\mathrm{p}$ can lead you to suspend judgment about $\mathrm{p}$, even though you are in possession of good lower-order evidence for $\mathrm{p}$. Consider:

Wendy, a chemist, uses a strip of litmus paper to test the $\mathrm{pH}$ of some solution and comes to believe that the solution has a $\mathrm{pH}$ of 4.6. She then is told by a colleague, Dr. Nefarious, that the university's supply of litmus paper has been discovered to be defective: only $50 \%$ of the strips are reliable; the rest are worthless. Wendy is loath to wait for a new shipment of litmus paper, and considers sticking to her conclusion about the $\mathrm{pH}$ of the solution, but she concludes that it would not be reasonable for her to believe that the

respect for diverse interlocutors, defending a plurality of conceptions of the good; the permission to retain lower-order beliefs ensures that you still have a conception of the good to defend. However I do not want to suggest that a skeptic like Feldman couldn't defend political liberalism. Note also that Rawls' conception of the "reasonable" is surely distinct from the conception employed by contemporary epistemologists, given its explicit political dimension. 
solution has a $\mathrm{pH}$ of 4.6 , given her evidence. On this basis, she suspends judgment about the $\mathrm{pH}$ of the solution. It turns out, though, that Dr. Nefarious is lying about the litmus paper being defective.

So misleading higher-order evidence sometimes undercuts good lower-order evidence, resulting in your being "doomed to fall short of some rational ideal." (Christensen 2010, p. 212) But not always. I maintain that there are cases in which you have misleading higher-order evidence that warrants suspension of judgment about whether believing $\mathrm{p}$ is reasonable for you, but where it remains reasonable for you to believe $\mathrm{p}$, in virtue of your having good lower-order evidence for p. Consider:

Julia and Maria’s religious beliefs (\$3.1) are based on careful consideration of a common body of evidence, which objectively supports theism. Julia has rationally appreciated this fact and her theistic belief is based on said rational appreciation; Maria's irrational assessment of the evidence was caused by an anti-clerical prejudice. But since Julia regards Maria as her epistemic peer, she decides that she must suspend judgment about whether her theistic belief is reasonable. She decides that she and Maria will have to "agree to disagree" - and so continues to believe theism is true, but suspends judgment about whether this belief is reasonable.

On the view I am proposing, Julia's two doxastic attitudes here are both reasonable: her belief is reasonable because of the objective support it receives from her lower-order evidence; her suspension of judgment is reasonable for the familiar reasons (Feldman 2006, Christensen 2007): it would be arbitrary and dogmatic for her to insist that her belief is reasonable, and Maria's unreasonable, while regarding Maria as an epistemic peer. 
We should concede that this is "an epistemically bad state of affairs" (Bergmann 2005, p. 424).

But this is a consequence of the fact that misleading evidence, in general, puts you in an epistemically bad state of affairs. As Christensen argues, it can force the epistemically virtuous agent to fall short of a rational ideal. Indeed, when someone who believes $\mathrm{p}$ on the basis of good evidence comes to possess misleading higher-order evidence, that her lower-order evidence does not support $\mathrm{p}$, she is faced with three epistemically bad options: (i) to ignore her higherorder evidence and continue believing $\mathrm{p}$, (ii) to suspend judgment about $\mathrm{p}$, and fall short of the rational ideal of giving her lower-order evidence its due, or (iii) to continue believing p while suspending judgment about whether believing $\mathrm{p}$ is reasonable.

I have proposed that misleading higher-order evidence sometimes does and sometimes does not undercut good lower-order evidence. What is the difference between cases in which it does and cases in which it doesn't? A simple and elegant answer to that question is that misleading higherorder evidence undercuts good lower-order evidence when, and only when, it warrants belief that said lower-order evidence is not good. When mere suspension of judgment about the quality of your evidence is warranted, then there is no undercutting, and you are permitted to retain your lower-order belief. But you must give up your belief when you believe that your evidence for said belief is not good.

A more complex view (cf. Kelly 2005) is also available, on which the question of whether misleading higher-order evidence undercuts good lower-order evidence is a highly complex matter, depending on the degrees of quality of the both the misleading higher-order evidence and the good lower-order evidence. On the complex view, much will depend on the quality of the lower-order evidence, and there may be cases in which you ought to believe $\mathrm{p}$ (given the strength of your lower-order evidence) and believe that believing $\mathrm{p}$ is not be reasonable for you (given your higher-order evidence). So both Feldman's principle and the undercutting principle would be false. 
Whichever of these views we adopt, we should not deny that higher-order evidence sometimes makes a difference in determining reasonable lower-order belief, nor (more generally) that higher-order epistemic attitudes sometimes make a difference in determining reasonable lowerorder belief. Feldman (2005) considers the view that "there is an independence of object level and meta-level evidence," (2005, p. 110) such that evidence about evidence for $\mathrm{p}$ is never relevant to the question of whether to believe p. As Feldman argues (Ibid.), this would prohibit belief based on testimonial evidence. But denying Feldman's principle, or the undercutting principle for that matter, does not amount to endorsing such an independence view of the relationship between higher-order evidence and reasonable lower-order belief. What I am proposing in this paper is therefore a via media between two extremes. On the one hand, we have the independence view, which rejects any connection between higher-order epistemic attitudes and reasonable lower-order belief. On the other hand, we have considered Feldman (2005) and Huemer's (2011) views, which affirm a strong connection between higher-order epistemic attitudes and reasonable lower-order belief. In rejecting Feldman's principle as well as the independence view, we arrive at a moderate position between these extremes.

\subsection{The unavoidability of metaincoherence}

Recall Huemer's notion of "metacoherence": that of "an epistemically desirable relationship between beliefs and metabeliefs.” (2011, p. 2) You might motivate Feldman's principle by appeal to the idea that your doxastic attitudes ought always manifest metacoherence, i.e. your doxastic attitudes ought never manifest metaincoherence: you ought never adopt doxastic attitude A towards $\mathrm{p}$ while disbelieving or suspending judgment about whether $\mathrm{A}$ is the epistemically proper attitude to adopt towards p. But such metaincoherence is sometimes unavoidable. Imagine an extension to the case of Wendy the chemist (\$3.2):

Wendy is told by another colleague that Dr. Nefarious, lusting after competitive merit-based pay raises, has a history of spreading misinformation 
to interfere with her colleagues' research. Wendy now doesn't know what to believe! So she suspends judgment about the $\mathrm{pH}$ of the solution and she suspends judgment about whether suspending judgment about the $\mathrm{pH}$ of the solution is reasonable for her.

Wendy's doxastic attitudes are metaincoherent, but intuitively her response to the evidence is a reasonable one. Cases like Wendy's are possible because suspension of judgment can be reasonable or not reasonable. Just as it can be reasonable to suspend judgment about whether belief or disbelief is reasonable, it can be reasonable to suspend judgment about whether suspension of judgment is reasonable. In Wendy's case, this happens because Wendy finds herself unable to competently answer the question of the reasonable doxastic attitude to adopt concerning the $\mathrm{pH}$ of the solution. But when someone suspends judgment about $\mathrm{p}$ and about whether suspending judgment about $\mathrm{p}$ is reasonable, her doxastic attitudes are metaincoherent.

Metaincoherence is therefore sometimes unavoidable. Recognizing this should allay any lingering worries about rejecting Feldman's principle. For if we countenance the sometime permissibility of being metaincoherent by suspending judgment about $\mathrm{p}$, while suspending judgment about whether suspending judgment about $\mathrm{p}$ is reasonable (as in Wendy's case), why should we resist countenancing the sometime permissibility of being metaincoherent by believing $\mathrm{p}$, while suspending judgment about whether believing $\mathrm{p}$ is reasonable? We should not resist it, in any event, on the ground that metaincoherence is always irrational.

\section{$4 \quad$ Intellectual humility}

We have considered motivating Feldman's principle by appeal to the respect view (\$2.1), by appeal to evidentialism ( $\$ 2.3)$, and by appeal to a metacoherence requirement ( $\$ 4.2)$. Feldman’s principle (among others) could alternatively be motivated within the framework of virtue epistemology. David Christensen (2010), for example, writes that maintaining your belief in the 
face of peer disagreement "can seem dogmatic." (p. 206) Dogmatism is a vice that contrasts with intellectual humility, and you might argue that it would be dogmatic to continue believing $\mathrm{p}$ while suspending judgment about whether believing $\mathrm{p}$ is reasonable, and that the intellectually humble thing to do would be to suspend judgment about p. Recall Julia and Maria, who have suspended judgment about whether their respective beliefs are reasonable. You might think that it would now be dogmatic for Julia to persist in her conviction that God exists. To continue to insist upon p, while admitting that for all you know your belief is not reasonable, so the argument goes, seems viciously dogmatic. Is this right? If we are to resist this line of reasoning, we will need an alternative account of intellectual humility, on which believing $\mathrm{p}$ while suspending judgment about whether believing $\mathrm{p}$ is reasonable is not viciously dogmatic.

I propose that we conceive of intellectual humility as a matter of higher-order epistemic attitudes:

Intellectual humility is the disposition to not adopt epistemically improper higher order epistemic attitudes, and to adopt (in the right way, in the right situations) epistemically proper higher-order epistemic attitudes.

Higher-order epistemic attitudes, recall, are doxastic attitudes about the epistemic status of your doxastic attitudes. An epistemically proper attitude is an attitude that you epistemically ought to adopt, and an epistemically improper attitude is one you ought not adopt. I assume that if someone ought to believe $\mathrm{p}$, then she ought not adopt any other doxastic attitude towards $\mathrm{p}$. Intellectual humility is a mean between two extremes (in the manner of moral virtues, according to Aristotle): intellectual dogmatism and intellectual timidity. The dogmatic overestimate the epistemic status of their doxastic attitudes; the timid underestimate the epistemic status of theirs. 
Suppose that Feldman is right that when epistemic peers disagree about p, they ought to suspend judgment about whether their respective doxastic attitudes towards $\mathrm{p}$ are reasonable. Intellectual humility, on the present conception, would require that neither person persist in believing that her belief is reasonable. It would be dogmatic, in such a situation, for someone to continue believing that her doxastic attitude is reasonable, and not the attitude of her peer. But intellectual humility, so understood, does not require either person to change her doxastic attitude towards p.

Note well the Aristotelian idea that the intellectually humble will adopt the proper attitude "in the right situations." When reflecting on a conversation with a disagreeing peer, it seems virtuous to adopt some attitude about the epistemic status of your belief. It is no manifestation of virtue to sit at home enumerating the many trivial and unremarkable things that you know, e.g. that $2+2=4$. Even if the epistemically proper attitude to take, concerning your belief that $2+2=4$, is the belief that you do indeed know that $2+2=4$, we should not say that adopting this attitude would be a manifestation of the virtue of intellectual humility. ${ }^{13}$

Suppose that Julia and Maria, given that they are disagreeing peers, ought to suspended judgment about whether their respective religious beliefs are reasonable. On the present account, intellectual humility requires that neither person believe that her belief is reasonable, and it allows us to say that both ought to suspend judgment about whether her belief is reasonable. If reasonable belief is necessary for knowledge, then intellectual humility will also require Julia to suspend judgment about whether she knows that God exists and it will require Maria to suspend judgment about whether she knows that that God doesn't exist. But it would not manifest intellectual humility for Julia to give up believing in God, in response to her disagreement with Maria. Julia should give up thinking that she knows that God exists. Her intellectual humility will

\footnotetext{
${ }^{13}$ We also require that the intellectually humble person adopt her higher-order epistemic attitudes "in the right way": someone who suspends judgment merely because she is afraid of offending people, even if suspension is the epistemically proper attitude, is not manifesting intellectual humility.
} 
be manifested in the following thought: "I believe that God exists, but I do not know whether this belief amounts to knowledge; I do not know whether I know that God exists."

The principal virtue of the present account is that it allows us to reject Feldman's Principle and preserve naïve liberalism. But its appeal can be strengthened by some observations about some related virtues and vices.

Compare intellectual humility, dogmatism, and timidity, which are virtues and vices of the mind, with dialectical humility, dialectical dogmatism, and dialectical spinelessness, which are virtues and vices of conversation, communication, and interpersonal interaction. The dialectical dogmatist is "dogmatic" in the sense that she employs dogmatic language, insisting that she is reasonable and the other party unreasonable, that she knows the truth and the other party doesn't. The dialectically humble person does the reverse: she admits that she may be wrong, and that the other party's position may be reasonable. One virtue of our account of intellectual humility is that it explains a connection between intellectual humility and dialectical humility. Given a sincere person (whose words and actions correspond to her thoughts and feelings), intellectual humility would give rise to dialectical humility, and dialectical humility would give rise to intellectual humility. ${ }^{14}$

We should also expect the intellectually humble person to treat her disagreeing interlocutors in a respectful way. For we can expect someone who has the proper perspective on the epistemic status of her own doxastic attitudes to have a proper perspective on the epistemic status of her interlocutors doxastic attitudes as well. This, on the assumption that underestimation of the epistemic statuses of other people's doxastic attitudes tends to derive from intellectual dogmatism. The dogmatist insists that her beliefs amount to knowledge, and this leads her to insist that others are ignorant. The intellectually humble person, when it is proper, admits that

${ }^{14}$ Cf. Benjamin Franklin's critical discussions of dogmatic language in his Autobiography. 
her beliefs may not amount to knowledge - and has no motive for denouncing her interlocutors as ignorant.

To allow your beliefs to be influenced by others in the way Feldman says you should seems a manifestation of a vice that Kant called intellectual immaturity, and which can contrasted with intellectual autonomy, or what Kant called "enlightenment." 15 This is the virtue of thinking for yourself, of not letting your options be guided improperly by others. It is natural, given the present account of intellectual humility, to conceive of intellectual autonomy as a matter (at least partially) of adopting proper first-order doxastic attitudes: the intellectually autonomous person is properly free from other's guidance when it comes to her first-order beliefs. There is room to argue about the scope of proper and improper guidance by others in your first-order beliefs (cf. \$3.2). But it is a virtue of the present account that it allows us to see clearly how intellectual autonomy and intellectual humility are compatible. Feldman's principle makes this opaque, if not problematic.

The account sketched may be overly narrow, in the sense that more may be required for intellectual humility. You might think, for example, that humility requires that you rethink your position when confronted with peer disagreement, or that you defer to experts when you are in an inferior epistemic position. What is important here is that intellectual humility is conceived of as not requiring modification of your doxastic attitude towards $\mathrm{p}$ in response to peer disagreement about p. More than I have suggested here may be required, in response to such disagreement; and more may be required for intellectual humility. But changing your doxastic attitude towards $\mathrm{p}$ is not.

The present conception of intellectual humility, dogmatism, and timidity seems to conflict with Thomas Kelly's (2011) account of the virtue of "following the argument where it leads," which he contrasts with the vice of dogmatism. Following the argument where it leads requires

${ }^{15}$ In 'What is Enlightenment?" (Kant 1970, pp. 54-60). 
reasonable doxastic attitudes plus typical "modalized reasonableness" - your belief that p will manifest this virtue when it is both reasonable and when were it not reasonable to believe $\mathrm{p}$, then you would not believe p (Ibid. p. 112). Dogmatism, on this view, is manifested by beliefs that fail to exhibit modalized reasonableness (Ibid. p. 108) - e.g. a conviction that you refuse to give up in the face of conclusive evidence against it, perhaps because of some bias, prejudice, or other species of motivated irrationality.

However, on reflection, there is no deep conflict here. Following the argument where it leads (and the contrasting vice of dogmatism) is not a matter of your higher-order epistemic attitudes, but rather a matter of the reasonableness and modalized reasonableness of your beliefs in general, including your first-order beliefs. Intellectual humility (and the contrasting vice of dogmatism) is a matter of your higher-order epistemic attitudes, and is not a matter of the reasonableness and modalized reasonableness of your beliefs in general. But we do not have two competing accounts of some virtue and its corresponding vice, but rather two compatible accounts of two different virtues and their corresponding vices.

There might be trouble here if our project were conceptual analysis or the provision of a semantics for ordinary language, if we were concerned (e.g.) with giving an account of dogmatism that jibes with ordinary use of the word "dogmatic." But we are free to say that "dogmatic" is ambiguous, and that useful clarity is provided by my sense of "intellectual dogmatism," Kelly's sense of "dogmatism," and the above sense of "dialectical dogmatism."

Note also that Kelly's account of following the argument where it leads does not entail Feldman's principle. What Kelly's account entails is that reasonableness and modalized reasonableness is a "genuine intellectual ideal." (Ibid. p. 107) This is consistent with any theory of reasonable belief, including theories on which Feldman's principle is false.

\section{Conclusion}


I have criticized arguments for Feldman's principle (\$2) and argued against it by appeal to naïve liberalism (\$3). Furthermore, I have proposed an account of intellectual humility (\$4) as the disposition to not adopt unreasonable higher-order epistemic attitudes, and to adopt reasonable higher-order epistemic attitudes. All this suggests an alternative approach in the epistemology of disagreement, on which the question of the proper response to disagreement about $\mathrm{p}$ concerns the proper higher-order doxastic attitude to adopt about the epistemic status of your doxastic attitude towards $\mathrm{p}^{16}$

\section{Bibliography}

Bergmann, M. (2005), "Defeaters and Higher-Level Requirements," The Philosophical Quarterly 55:220, pp. 419-36.

Chisholm, R. (1989) Theory of Knowledge, third edition (Prentice-Hall).

Christiansen, D. (2007), "Epistemology of Disagreement: The Goods News,” Philosophical Review 116, pp. 187-217.

---- (2010), “Higher-Order Evidence," Philosophy and Phenomenological Research 81:1, pp. 185-215.

DeRose, K. (2002), “Assertion, Knowledge, and Context,” Philosophical Review 111, pp. 167-203.

Elga, A. (2007), "Reflection and Disagreement," Noûs 41:3, pp. 478-502.

Feldman, R. (2005), “Respecting the Evidence,” Pbilosopbical Perspectives 19, pp. 95-119.

(2006), “Epistemological Puzzles about Disagreement," in S. Heatherington (ed.), Epistemology Futures (Oxford University Press), pp. 216-36.

\footnotetext{
${ }^{16}$ I presented this paper at Dartmouth College in the summer of 2011; thanks to the philosophers there for their comments and suggestions, as well as to my anonymous referees at this journal.
} 
----- (2007), “Reasonable Religious Disagreements," in L. Antony (ed.), Philosophers Without Gods (Oxford), pp. 194-214.

Huemer, M. (2011), “The Puzzle of Metacoherence,” Philosophy and Phenomenological Research 82:1, pp. 1-21.

Moore, G.E. (1993), Selected Writings (Routledge).

Kant, I. (1970), Political Writings (Cambridge University Press).

Kelly, T. (2005), “The Epistemic Significance of Disagreement,” Oxford Studies in Epistemology 1, pp. 167-96.

----- (2011), "Following the Argument Where it Leads," Philosophical Studies 154, pp. 105-24.

Rawls, J. (1996) Political Liberalism (Columbia University Press).

Weiner, M. (2005), “Must We Know What We Say?,” Philosophical Review 114:2, pp. 227-51.

Williamson, T. (1996), “Knowing and Asserting,” Philosophical Review 105, pp. 489-523.

----- (2001), Knowledge and Its Limits (Oxford University Press). 